\title{
O comportamento pós-crise financeira das taxas de câmbio no Brasil, China, Índia e Europa
}

\author{
Guilherme R. S. Souza e Silva*
}

\begin{abstract}
RESUMO - O presente artigo apresenta e discute o comportamento das taxas de câmbio do Brasil, China, Índia e Europa considerando o período pós-crise financeira internacional. O estudo compara o desempenho das moedas dos países selecionados e as estratégias utilizadas pelas autoridades monetárias, bem como avalia os efeitos, especialmente sobre o comércio internacional, do comportamento da taxa de câmbio. Ao longo do artigo destacam-se as diferenças entre a condução das políticas cambiais nos países estudados, mostrando que a China, apesar de não demonstrar explicitamente, adota um regime de câmbio fixo de facto, e que também a Índia, numa escala menor, adota comportamento semelhante. No caso do Brasil, que em muitos aspectos é comparado aos dois países anteriores, não se observa claramente uma tentativa de fixação da taxa de câmbio, o que resulta em uma diferente estratégia de política cambial. Finalmente avalia-se a questão da taxa de câmbio na Europa, que em função da moeda única apresenta características ímpares em relação às demais.
\end{abstract}

Palavras-Chave: Taxa de câmbio. Comércio internacional. Exportações brasileiras.

\section{INTRODUÇÃO}

Este artigo tem o objetivo de apresentar e analisar o comportamento das taxas de câmbio de moedas selecionadas em relação ao dólar americano no período após o pico da crise financeira internacional recentemente enfrentada pelas principais economias do mundo.

A ideia é comparar o desempenho da taxa de câmbio no Brasil com o desempenho da taxa de câmbio em outros países e avaliar os possíveis impactos do câmbio sobre o desempenho do comércio internacional. Para tanto, o artigo está dividido em 5 tópicos, sendo o primeiro a presente introdução; o segundo a escolha dos dados e do período de análise; o terceiro a apresentação dos comportamentos das taxas de câmbio; o quarto a análise dos resultados e o quinto as conclusões do estudo.

Serão apresentadas as variações das taxas de câmbio do Brasil, China, Índia e Zona do Euro em relação ao dólar americano. O período selecionado foi desde o início de 2009, momento em que a crise financeira internacional ainda preocupava fortemente as economias,

\footnotetext{
* Mestre em Desenvolvimento Econômico pela Universidade Federal do Paraná (UFPR). Professor do Setor de Educação Profissional e Tecnológica da UFPR. Endereço eletrônico: guilherme.ricardo@ufpr.br.
} 
até maio de 2010, quando a Europa passou a ser o centro das preocupações, em função da crise da dívida da Grécia.

\section{O PERÍODO DE ANÁlISE E A SELEÇÃO DAS MOEDAS}

Para avaliarmos o desempenho recente da taxa de câmbio no Brasil foram selecionadas outras três moedas para a realização dos comparativos. Foram escolhidos o yuan chinês e a rúpia indiana, por se tratarem de países emergentes que, em alguns aspectos, podem ser comparados ao Brasil e o euro, por se tratar da moeda representativa da economia de vários países da Europa, tendo grande importância no comércio internacional, e que recentemente encontra-se em um período de grande fragilidade.

Quanto ao período analisado, é importante lembrarmos que diversos analistas consideram o mês de outubro de 2008 como o auge da crise financeira internacional, que atingiu fortemente os mercados financeiros mundiais, em especial o norte-americano. Ao longo do ano de 2009 as diversas economias recuperaram-se em diferentes ritmos, em função de seus problemas domésticos e de suas posições no comércio internacional. No caso brasileiro, a indústria começou a mostrar sinais de recuperação a partir do mês de abril de 2009 e desde então passou a exibir taxas crescentes de aumento na produção. Considerando o período mais recente tivemos, principalmente a partir de abril de 2010, o agravamento da crise da dívida pública da Grécia, que trouxe uma grande instabilidade para a moeda da zona do euro.

Dessa forma, faremos a apresentação dos comportamentos das taxas de câmbio considerando dois períodos. O primeiro mais amplo, que vai de 02 de janeiro de 2009, quando a crise financeira internacional ainda estava em evidência até 21 de maio de 2010, compreendendo os dados mais recentes disponíveis. O segundo período analisado foi menor, de forma a tentar separar os efeitos das crises, compreendendo o mês de junho de 2009 até março de 2010. Foi utilizada a taxa de câmbio nominal para efetuar as comparações, uma vez que os períodos de análise não são muito longos e as taxas de inflação nos países avaliados não apresentaram no período valores excessivamente altos. Os dados foram obtidos a partir da base de informações do Federal Reserve Bank de St. Louis.

\section{O COMPORTAMENTO DAS TAXAS DE CÂMBIO}

A gráfico 1 abaixo, apresenta a variação das taxas de câmbio entre as moedas selecionadas e o dólar americano. Considerou-se como valor de referência a taxa de câmbio

40 
nominal no dia 02 de janeiro de 2009 (equivalente a 100\%). A partir deste ponto estão calculados os valores da taxa de câmbio em relação a esta referência. É importante destacar que a taxa de câmbio considerada é o preço de US\$1,00 em moeda doméstica, de modo que uma queda apresentada no gráfico corresponde a uma apreciação da moeda nacional. Por exemplo, no Brasil em 02 de janeiro de 2009, US\$1,00 era comprado por R\$2,32 (equivalente a $100 \%$ do valor de referência) e em 21 de maio de 2010 US $\$ 1,00$ era comprado por $\mathrm{R} \$ 1,85$ (equivalente a $80 \%$ do valor de referência).

\section{GRÁFICO 1 - TAXAS DE CÂMBIO NOMINAIS DE JAN/2009 A MAI/2010}

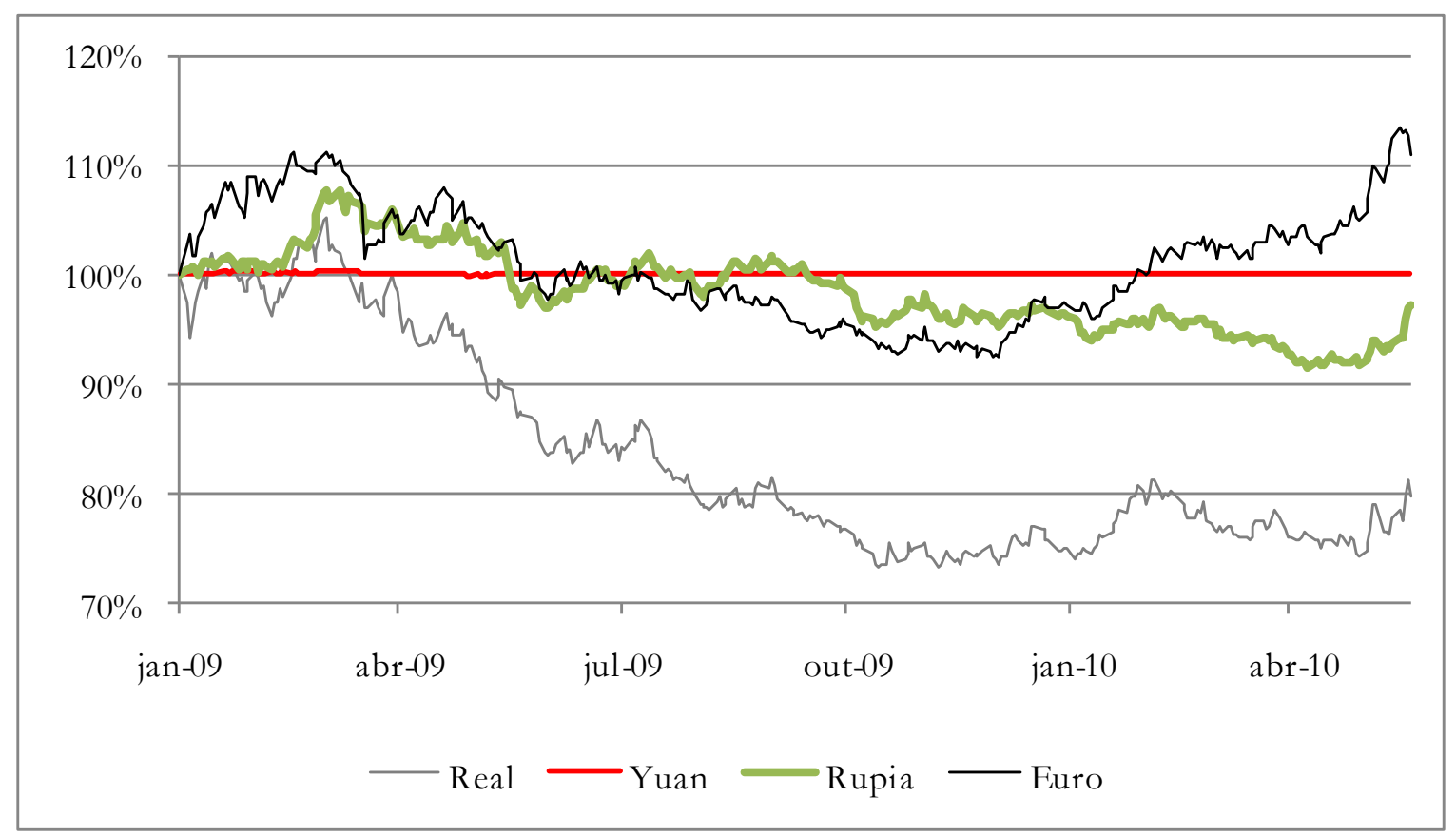

FONTE: Elaboração própria a partir de dados do Federal Reserve Bank of St. Louis.

A avaliação da gráfico 1 nos permite a elaboração de algumas observações. Em primeiro lugar destaca-se o comportamento da moeda chinesa, o yuan, que ao longo do período mantém a taxa de câmbio com o dólar americano praticamente constante. Pode-se verificar que a China, apesar de não admitir explicitamente, mantém um regime de câmbio fixo de facto. No próximo tópico discutiremos algumas das implicações dessa política cambial chinesa e a reação dos países que mantém um forte comércio internacional com a China.

Em seguida, observando o comportamento do real, verificamos que a moeda brasileira manteve um forte ritmo de apreciação ao longo do período, de modo que o preço do dólar em real, em maio de 2010, reduziu-se para cerca de $80 \%$ do valor no início do período. Entre as moedas avaliadas foi a que apresentou a maior apreciação em relação ao dólar americano no período. 
A rúpia indiana apresentou um comportamento oscilante ao longo do período avaliado, alternando momentos de apreciação e depreciação em relação ao dólar, porém com flutuações de baixa intensidade. No entanto, mais para o final do período a rúpia apresentou tendência constante de apreciação, porém o preço do dólar em rúpias em nenhum momento chegou a menos de $90 \%$ do valor no início do período.

Finalmente o euro apresentou um comportamento bastante flutuante, demonstrando também momentos de apreciação e depreciação em relação ao dólar. Assim como no caso da rúpia, a apreciação do euro em nenhum momento fez com que o preço do dólar em euros chegasse a menos de $90 \%$ do seu valor no início do período. Especialmente no final do período, no entanto, o preço do dólar chegou a mais de 110\% de seu valor inicial, questão que será discutida no próximo tópico e que está diretamente relacionada à recente crise da dívida pública de alguns países da zona do euro.

Com o objetivo de tentar separar os impactos das crises nas avaliações do comportamento das taxas de câmbio foi realizado o mesmo comparativo que o apresentado acima, porém considerando um período mais curto e menos influenciado pelas crises financeiras. A gráfico 2 abaixo, apresenta o comparativo considerando o período de 01 de junho de 2009 a 31 de março de 2010.

A gráfico 2 apresenta um comportamento muito semelhante ao gráfico 1, observando-se apenas uma menor intensidade nas flutuações. As tendências, entretanto, são muito semelhantes e novamente o real aparece como a moeda que apresentou maior apreciação em relação ao dólar tanto no final como ao longo de praticamente todo o período. No próximo tópico discutiremos algumas possíveis causas e consequências dos comportamentos cambiais apresentados nesse tópico.

\section{ANÁLISE DO COMPORTAMENTO DAS TAXAS DE CÂMBIO}

A observação dos comportamentos das taxas de câmbio levanta uma série de questões interessantes a serem debatidas e analisadas mais profundamente. Inicialmente analisaremos o caso da taxa de câmbio na China.

Conforme apresentado no tópico 3, a taxa de câmbio na China de facto assemelha-se muito a um regime de câmbio fixo, com constantes intervenções do Banco Central no mercado de câmbio com o objetivo de manter a paridade com o dólar fixo. Esse comportamento do Banco Central da China vem sendo questionado por diversos países, em 
especial pelos Estados Unidos e Europa. De fato, desde 2003 considera-se $^{1}$ que existe uma pressão sobre o Banco Central da China para que seja permitida a flutuação da moeda chinesa, de modo que a mesma não seja mantida fixa pelas autoridades monetárias chinesas.

GRÁFICO 2. TAXAS DE CÂMBIO NOMINAIS DE JUN/2009 A MAR/2010

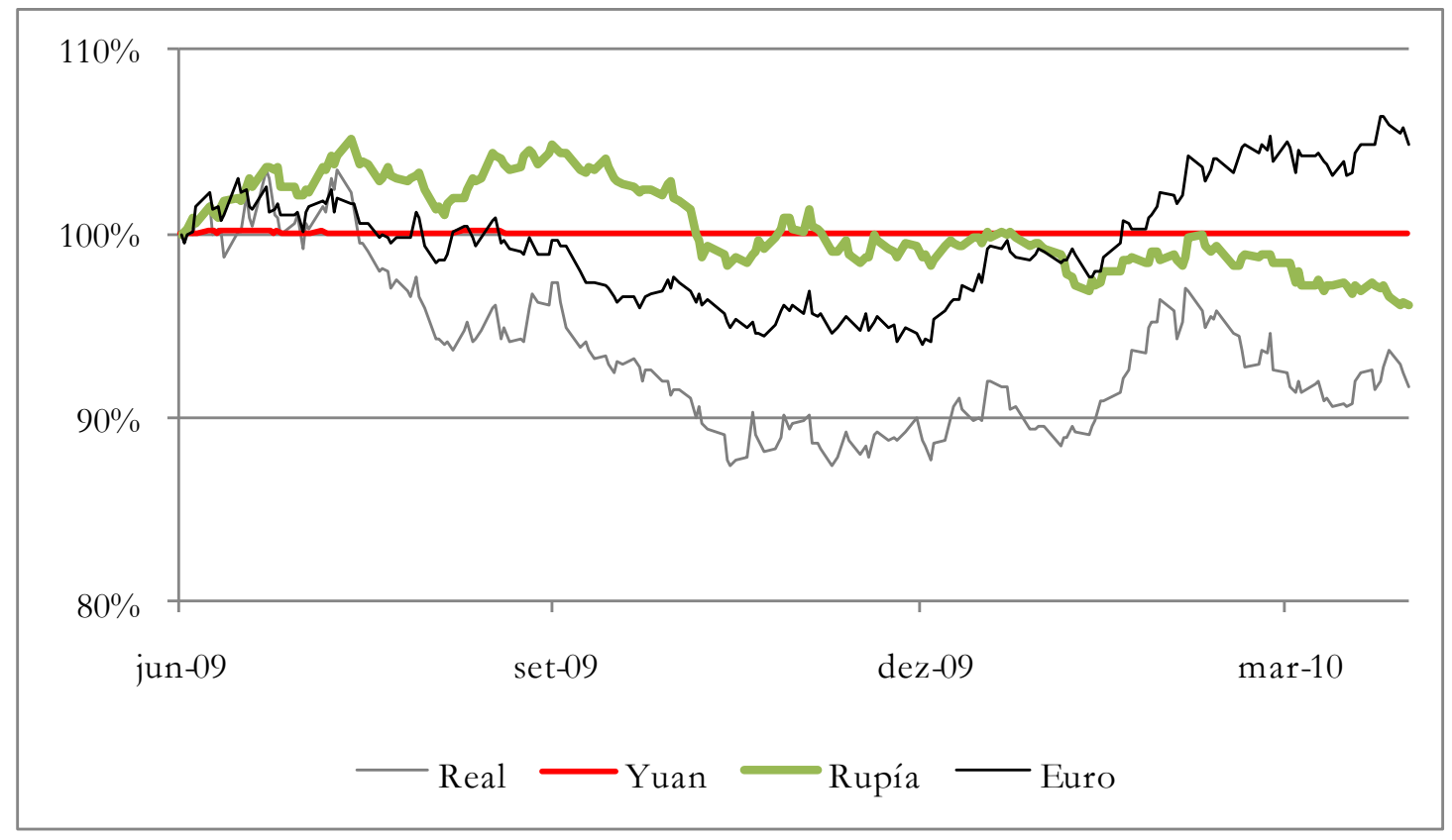

FONTE: Elaboração própria a partir de dados do Federal Reserve Bank of St. Louis.

A questão debatida nesse caso trata da utilização da taxa de câmbio pela China como instrumento para aumentar a competitividade de suas exportações. De fato, é praticamente consenso o fato de que a manutenção de uma taxa de câmbio artificialmente depreciada faz com que as exportações do país tornem-se mais competitivas em relação às exportações dos demais países, pois com a mesma quantidade de dólares, que atualmente servem como meio de troca para a maioria das transações internacionais, é possível a compra de uma maior quantidade de mercadorias se a moeda chinesa encontra-se desvalorizada.

Esse debate, no entanto, acaba sendo bastante delicado, uma vez que conforme apresentado por diversos autores, em especial por Eichengreen (2004) e Papadimitriou et al. (2006), a China acumulou nos últimos anos uma grande quantidade de títulos em dólares e euros, tornando a relação entre Estados Unidos e China algo como uma simbiose que vem sendo mantida por interesse das duas grandes nações, possibilitando o crescimento econômico e a criação de empregos na China e a manutenção de altos níveis de consumo nos Estados Unidos.

${ }^{1}$ Conjuntura Internacional - PUC Minas - junho de 2005. 
Quando analisamos o comportamento da moeda brasileira a situação é bastante diferente. Fica bastante claro que a taxa de câmbio no Brasil é de facto flutuante e que o país, ao contrário da China, não vem utilizando a taxa de câmbio intencionalmente como instrumento para favorecimento de suas exportações. Esta é, aliás, uma das principais reclamações do setor exportador brasileiro, que questiona o fato de o Banco Central do Brasil não intervir fortemente no câmbio, permitindo a apreciação da moeda brasileira, enquanto outros países competidores no comércio internacional utilizam intencionalmente o câmbio como ferramenta para aumento das exportações.

Se pelo lado das exportações a apreciação do real é algo negativo, pelo lado da estabilidade monetária e do posicionamento do Brasil na Economia mundial a força da moeda brasileira é considerada algo positivo. De fato, quando analisamos o passado da economia brasileira, as crises internacionais costumavam ter um impacto extremamente forte sobre a taxa de câmbio brasileira, que gerava crises no balanço de pagamentos e sérios problemas em relação à dívida externa brasileira. O Brasil passou por diversas crises cambiais, muitas vezes geradas por instabilidades em outros países, mas que por efeito cascata atingiam fortemente a economia brasileira. Em relação à crise financeira recente, pode-se dizer que o Brasil foi um dos países que apresentou boa recuperação e quanto à atual crise na Europa, até o momento, os impactos parecem estar restritos ao mercado financeiro brasileiro, em especial às bolsas de valores.

Quando se discute a questão câmbio é preciso levar em conta que o comportamento cambial é uma resultante de diversas variáveis, como o próprio comércio internacional, o desempenho do setor financeiro e das atividades especulativas e o posicionamento da economia em questão no cenário global. Nesse sentido, as flutuações recentes do real vêm demonstrando que a economia brasileira é considerada sólida pelos agentes econômicos e que o comércio internacional vem permitindo que o Brasil mantenha controlado o comportamento do seu balanço de pagamentos.

Avaliando o comportamento do euro, a situação é praticamente contrária ao real brasileiro. Especialmente a partir de abril de 2010 o euro vem sofrendo uma forte depreciação em relação ao dólar, fruto principalmente da crise da dívida pública que assolou a Grécia e ao possível agravamento de uma crise semelhante na Espanha. Essas situações demonstraram uma possível fragilidade do euro, especialmente em função de o Banco Central Europeu executar uma política monetária única para os países da zona do euro, enquanto as políticas fiscais são independentes em cada país. 
Mesmo antes do agravamento da crise, o euro já vinha dando sinais de enfraquecimento, sendo que praticamente desde o início de dezembro de 2009 o euro vem se depreciando em relação ao dólar americano. Ainda não se podem afirmar ao certo quais serão os desdobramentos da atual crise na Europa, mas as dúvidas em relação à estabilidade e à força da moeda única seguramente se tornaram maiores.

Quanto ao comportamento da moeda indiana, a rúpia, observa-se uma menor flutuação quando comparada ao euro e ao real brasileiro. A moeda da Índia registrou uma tendência de depreciação no início de 2009, mas a partir de março de 2009 a rúpia apresentou uma tendência constante de apreciação em relação ao dólar, porém com uma intensidade bastante inferior à apreciação do real brasileiro.

Conforme demonstrado por Paula (2005), assim como na China, na Índia a taxa de câmbio flutua menos principalmente em função de intervenções do Banco de Reserva da Índia (RBI). Segundo o autor, o RBI utiliza diversos instrumentos para influenciar as condições do mercado cambial, intervindo no mercado spot (à vista), utilizando transações futuras e de swap de câmbio e buscando acumular reservas para sustentar suas intervenções no mercado cambial. Assim, verifica-se que em dois dos maiores países do grupo denominado emergentes, a taxa de câmbio, na prática, é diretamente influenciada pelas autoridades monetárias com o objetivo de favorecer a competitividade das exportações.

\section{CONCLUSÕES}

O estudo apresentado nos permite a elaboração de algumas conclusões em relação ao tema proposto. O ponto principal a ser observado é o fato de a moeda brasileira estar em um processo de apreciação em relação ao dólar americano, apresentando um comportamento bastante diferenciado no período pós-crise financeira das demais moedas avaliadas: euro, yuan e rúpia. Principalmente no caso chinês, e em grau um pouco menor no caso indiano, fica bastante evidente a utilização da taxa de câmbio como instrumento de favorecimento das exportações.

Nesse sentido, diversos analistas questionam o posicionamento "neutro" do Banco Central do Brasil e a consequente possível perda de competitividade das exportações brasileiras, que em alguns setores tem como concorrentes diretos os países anteriormente mencionados. Por outro lado, a estabilidade e o prestígio da moeda brasileira em momentos críticos da economia internacional colocam o país em um novo patamar em relação às crises 
anteriores, em que a economia brasileira era fortemente afetada por flutuações no câmbio que geravam crises no balanço de pagamentos e problemas em relação à dívida externa.

Finalmente caberá a partir de agora a avaliação do comportamento da taxa de câmbio na Zona do Euro e os desdobramentos das crises nos países europeus mais afetados. A estabilidade do euro e a manutenção da moeda única dependerão de como as economias europeias irão reagir a problemas que até então não tinham sido enfrentados pela moeda única.

\section{REFERÊNCIAS}

EICHENGREEN, B. Global Imbalances and the Lessons of Bretton Woods. NBER Working Series Papers, n.10497, Cambridge.

MENDES, D. F. Taxa de câmbio chinesa. Conjuntura Internacional - PUC MINAS (Cenários). Junho de 2005.

PAPADIMITRIOU, D. B.; ZEZZA, G.; HANNSGEN, G. Can global imbalances continue? Policies for the U.S. economy. New York: The Levy Economics Institute of Bard College.

PAULA, L. F. O diabo é que na China e na Índia o câmbio não flutua. Jornal Valor Econômico. 